\title{
Optimization studies on pre-gelatinized sweet potato starch influenced by temperature and time
}

\author{
*Ulfa, G.M., Putri, W.D.R., Fibrianto, K. and Widjanarko, S.B. \\ Department of Food Science and Technology, Faculty of Agricultural Technology, Universitas Brawijaya, \\ Jalan Veteran No. 1, Ketawanggede, Malang, Indonesia 65145
}

\begin{abstract}
Article history:
Received: 7 December 2020

Received in revised form: 25

March 2021

Accepted: 10 June 2021

Available Online: 20 June

2021
\end{abstract}

Keywords:

Optimization,

pre-gelatinization,

Sweet potato starch,

Temperature,

Time

DOI:

https://doi.org/10.26656/fr.2017.5(S2).017

\begin{abstract}
Starch is a unique polysaccharide that is widely used as a thickener, filler, and gelling agent. Indonesia is one of the largest, sweet potato producers that can be used as a source of starch. Not much is known from the utilization of sweet potato starch because of its less popularity compared to potato or cassava starch. Besides, sweet potato starch in its native state has various disadvantages such as low solubility, low stability, and high retrograde tendency. These starch limitations can be overcome by modifying the starch. Starch pregelatinization is a physical modification method carried out by heating the starch above its gelatinization temperature. This research was aimed to optimize the temperature and time of sweet potato starch pre-gelatinization. The response surface method (RSM) with a central composite design (CCD) was used to create a process model. The use of $59.53^{\circ} \mathrm{C}$ for 15.00 mins showed that had the most optimum characteristics in solubility, swelling power, and water-binding capacity. SEM analysis also showed that starch had larger starch granules and some granules had melted which shows that partial pre-gelatinization had occurred.
\end{abstract}

\section{Introduction}

Indonesia is one of the largest producers of sweet potato that contribute to the world's total production. There is an increase in Indonesia's total sweet potato production from about 101 million tonnes in 2012 up to 105 million tonnes in 2016 (FAOSTAT, 2020). However, the utilization of sweet potato in Indonesia is still limited to direct consumption. Besides, the potential of sweet potato starch is inferior to other sources of starch such as corn and cassava (Ulfa et al., 2019).

Sweet potato starch usage in the food industry is still less popular due to its disadvantages. Its native state disadvantages such as low solubility, low stability, and high retrograde tendency (Ulfa et al., 2019) limit sweet potato starch potential. These drawbacks could be overcome by starch modification. Starch modification could be done by physic, chemical, enzymatic, and genetic engineering method. Physical modification is a simple, easy, and low-cost method that can be used in modifying starch (Zia-ud-Din et al., 2015). Pregelatinization is the physical modification methods that improve starch functional characteristics (Ulfa et al., 2020). This method is known to improve some physical characteristics. Pre-gelatinization could improve the flowability of some cereals starch with the increase of swelling power and water-binding of starch (Alebiowu and Itiola, 2002; Liu et al., 2017). These characteristics favor the making of tablet formulation (Kankate et al., 2020). The increase of solubility, swelling power, and water-binding ability also happened in pre-gelatinized Dioscorea (Odeku et al., 2008), sorghum, banana, corn (Alebiowu and Itiola, 2002), yam, and rice starch (Adedokun and Itiola, 2010). This increment will favor the making of instant products (Butt et al., 2018).

When starch suspension with an excessive amount of water is heated above its gelatinization temperature and limited shear, the starch granule expands and loses its birefringence. The full or partial gelatinization could occur if these processes were allowed to proceed for some time (Liu et al., 2010; Ulfa et al., 2020). The crystalline region is irreversibly broken at a certain point and the gelatinization is initiated. These processes are influenced by the process temperature and time (Ulfa et al., 2020). Based on the author's knowledge, there are no studies reported on the optimization process in pregelatinization temperature and time of sweet potato starch. Therefore this study was aimed to optimize the pre-gelatinization process. The starches were analyzed to 
evaluate the effect of temperature and time in pregelatinization.

\section{Materials and methods}

\subsection{Preparation of modified starch and research design}

Native sweet potato starch was obtained from Yogyakarta, Indonesia $\left(7^{\circ} 38^{\prime} 42^{\prime \prime} \mathrm{S} 110^{\circ} 1^{\prime} 37^{\prime \prime} \mathrm{E}\right)$. Pregelatinized starch was prepared by using the method from (Ulfa et al., 2020). The starch suspension (100 g in $100 \mathrm{~mL}$ of distilled water) was made in a $250 \mathrm{~mL}$ beaker glass. The suspension was heated in a shaker water bath with design temperature and time. The paste from the process was dried in an oven at $50^{\circ} \mathrm{C}$ for $24 \mathrm{hrs}$. The starch was ground and kept in a bottle with food-grade silica gel.

The response surface method with a central composite design was used to optimize the effect of independent variables toward the responses. The analysis was carried out using Design Expert (11.0 version, StatEase, USA). The setup design for the software (Tables 1 and 2), consisted of two factors which were temperature and reaction time. The levels of independent variables were determined by previous work at $35-60^{\circ} \mathrm{C}$ (Ulfa et al., 2020). The responses were solubility, swelling power, and water-binding capacity. The design suggested by the software were thirteen experimental runs with five repetitions as center points. The ANOVA was obtained from the software and the optimized parameters had 3 solutions that were validated in the experiment.

Table 1 . The variables and levels in experimental design

\begin{tabular}{lcccccc}
\hline & & \multicolumn{5}{c}{ Levels } \\
\cline { 3 - 7 } Variables & Factors & $-\alpha$ & -1 & 0 & 1 & $\begin{array}{c}+\alpha \\
(+1.41)\end{array}$ \\
\hline Temperature $\left({ }^{\circ} \mathrm{C}\right)$ & $\mathrm{X}_{1}$ & 35.86 & 40 & 50 & 60 & 64.14 \\
Reaction time $(\mathrm{min})$ & $\mathrm{X}_{2}$ & 2.93 & 5 & 10 & 15 & 17.07 \\
\hline
\end{tabular}

\subsection{Physicochemical analysis}

The analysis of ash and moisture were performed following the AOAC procedures (AOAC, 2005), solubility, swelling power, and water-binding capacity following the method by Kaur et al. (2011), pH with $\mathrm{pH}$ meter (Trans Instruments, Singapore), amylose following the method by Juliano (1981), total starch content by acid hydrolysis method by Pirt and Whelan (1951), and color analysis using CIE whiteness index by Zhu and Sun (2019).

\subsection{Atomic bonding, pasting, and morphology} characteristics analysis

Fourier transform infrared (8400S, Shimadzu, Japan) spectrometer was used to analyze the bonding between atoms of all the starches with potassium bromide $(\mathrm{KBr})$ discs. Spectrum was scanned between $400 \mathrm{~cm}^{-1}$ and 4000 $\mathrm{cm}^{-1}$.

Rapid visco analyzer (RVA) was used to examine the pasting properties of starches (RVA-TecMaster, Newport Scientific, Australia). The parameters observed were peak, breakdown, pasting temperature, viscosity, trough, setback, and peak time.

Scanning electron microscopy (TM3000, Hitachi, Japan) with palladium as sample coating were used to check the morphology of native and pre-gelatinized starch. The sample was scanned at $15 \mathrm{kV}$ accelerating potential in each run.

\section{Results and discussion}

\subsection{Physicochemical analysis}

The results of the physicochemical analysis of the native and treated starches are presented in Table 3. There was no change in ash content due to pregelatinization. The moisture content of pre-gelatinized

Table 2. The experimental design for optimizing the process of pre-gelatinization

\begin{tabular}{ccccccccc}
\hline \multirow{2}{*}{ Std } & Run & \multicolumn{9}{c}{ Variables } \\
\cline { 2 - 8 } & Code & Actual $\left({ }^{\circ} \mathrm{C}\right)$ & Code & Actual (Min) & Solubility (\%) & Swelling power (g/g) & Water-binding capacity (\%) \\
\hline 1 & 8 & -1 & 40 & -1 & 5 & 3.83 & 21.73 & 84.58 \\
2 & 1 & 1 & 60 & -1 & 5 & 6.91 & 27.24 & 98.82 \\
3 & 13 & -1 & 40 & 1 & 15 & 4.27 & 22.01 & 94.21 \\
4 & 11 & 1 & 60 & 1 & 15 & 5.95 & 28.76 & 91.37 \\
5 & 7 & -1.41 & 35.86 & 0 & 10 & 2.41 & 17.79 & 81.66 \\
6 & 5 & 1.41 & 64.14 & 0 & 10 & 4.72 & 26.32 & 93.75 \\
7 & 6 & 0 & 50 & -1.41 & 2.93 & 6.97 & 25.02 & 93.56 \\
8 & 3 & 0 & 50 & 1.41 & 17.07 & 6.22 & 31.88 & 98.98 \\
9 & 12 & 0 & 50 & 0 & 10 & 9.22 & 33.51 & 112.81 \\
10 & 10 & 0 & 50 & 0 & 10 & 8.82 & 33.94 & 109.84 \\
11 & 4 & 0 & 50 & 0 & 10 & 10.23 & 36.15 & 109.59 \\
12 & 2 & 0 & 50 & 0 & 10 & 9.78 & 31.26 & 113.46 \\
13 & 9 & 0 & 50 & 0 & 10 & 10.89 & 34.79 & 113.49 \\
\hline
\end{tabular}


starch was lower than the native starch. This change of moisture was influenced by the drying process. This reduction was also showed in pre-gelatinized banana, sorghum (Alebiowu and Itiola, 2002), cassava (Lawal et al., 2015) corn, yam, and rice (Adedokun and Itiola, 2010).

Table 3. The physicochemical properties of native and pregelatinized starches

\begin{tabular}{lcc}
\hline \multicolumn{1}{c}{ Parameters } & Native starch & $\begin{array}{c}\text { Pre-gelatinized } \\
\text { starch }\end{array}$ \\
\hline Ash content (\%) & $0.58 \pm 0.02$ & $0.59 \pm 0.01$ \\
Moisture content (\%) & $9.41 \pm 0.1$ & $8.67 \pm 0.05$ \\
Solubility (\%) & $1.54 \pm 0.01$ & $5.02 \pm 1.04$ \\
Swelling power (g/g) & $16.26 \pm 0.52$ & $33.12 \pm 1.04$ \\
Water-binding capacity (\%) & $76.07 \pm 0.66$ & $90.22 \pm 1.23$ \\
Amylose (\%) & $41.40 \pm 1.62$ & $43.08 \pm 1.15$ \\
Total starch (\%) & $93.92 \pm 1.60$ & $95.03 \pm 0.83$ \\
Whiteness index & $85.79 \pm 0.03$ & $86.02 \pm 0.02$ \\
\hline
\end{tabular}

Values are expressed as mean \pm SD of triplicates

The pre-gelatinized starch showed an increase in amylose, total starch, and whiteness index content. The disruption of starch granule could be responsible for these changes. The increase in amylose content is also found in yam, corn, and rice starch (Adedokun and Itiola, 2010). The value of solubility, swelling power, and water -binding capacity also increase after pre-gelatinization. These results are also found in Dioscorea (Odeku et al., 2008), and other cereal (Alebiowu and Itiola, 2002). These changes could happen due to the disruption inside starch granule and rearrangement of starch granule which enable the release of granule content (Wang et al., 2019; Ulfa et al., 2020). The increase of water-binding and swelling power were directly related to the value of solubility.

\subsection{Optimization results and analysis}

The experiment design for software analysis results is presented in Table 2. A model without a significant lack of fit and significant $\mathrm{R}^{2}$ suggested was the quadratic model. After that, the model was optimized with targeted criteria. The target was chosen from commercial potato starch parameters. Potato starch was chosen because of its good characteristics for industry (Mitch, 1983). The equations for the quadratic model on each parameter are presented below:

$$
\begin{aligned}
& y_{1}=+33.93+3.04 A+1.44 B+0.31 A B-6.02 A^{2}-2.82 B^{2} \\
& y_{2}=+9.79+1.00 A-0.19 B-0.35 A B-3.07 A^{2}-1.56 B^{2} \\
& y_{3}=+111.84+3.56 A+1.23 B-4.27 A B-12.00 A^{2}-7.72 B^{2}
\end{aligned}
$$

Where $y_{1}$ is the response variable (S), $y_{2}$ is the response variable (SP), $y_{3}$ is the response variable (WBC), $A$ is the temperature $\left({ }^{\circ} \mathrm{C}\right), B$ is reaction time (min), the interaction between temperature and reaction

Table 4. The analysis of variance from the analysis showing the effect of all factors $(\mathrm{p} \leq 0.05)$

\begin{tabular}{lccc}
\hline \multirow{2}{*}{ Factors } & \multicolumn{3}{c}{ p-value dependent variables } \\
\cline { 2 - 4 } & Solubility & $\begin{array}{c}\text { Swelling } \\
\text { power }\end{array}$ & $\begin{array}{c}\text { Water-binding } \\
\text { capacity }\end{array}$ \\
\hline Model-Quadratic & $<0.0001^{*}$ & $0.0003^{*}$ & $<0.0001^{*}$ \\
$A$-Temperature & $0.0036^{*}$ & $0.0016^{*}$ & $0.0009^{*}$ \\
$B$-Reaction time & 0.4265 & 0.0513 & 0.0985 \\
$A B$ & 0.3229 & 0.7282 & $0.0023^{*}$ \\
$A^{2}$ & $<0.0001^{*}$ & $<0.0001^{*}$ & $<0.0001^{*}$ \\
$B^{2}$ & $0.0004^{*}$ & 0.0036 & $<0.0001^{*}$ \\
Lack-of-fit & 0.9011 & 0.5438 & 0.6032 \\
\hline
\end{tabular}

*Significantly different at $95 \%$ confidence level

time $(A B)$, and the double of temperature $\left(A^{2}\right)$ and reaction time $\left(B^{2}\right)$. The synergistic effect was represented by the positive sign in front of the equation and vice versa for the antagonistic effect (Ani et al., 2019). The ANOVA for each response is presented in Table 4.

The effect of independent variables toward each response is presented in Figure 1. Three solutions obtained from the software were validated in the laboratory (Table 5). The validation showed that the optimum responses obtained at $59.53^{\circ} \mathrm{C}$ for 15.00 mins. When starch was heated in the presence of excess water, the crystalline structure will disrupt because of the loss of inter and intramolecular hydrogen bonds (Ulfa et al., 2020). The interaction between starch chains will affect the water-binding and the swelling ability of starch which directly relates to starch solubility. These interactions were determined by the ratio of amylose amylopectin, molecular weight, distribution of starch molecule, branch, and starch conformation (Hoover, 2001).

\subsection{Atomic bonding, pasting, and morphology characteristics analysis}

The bonding between atoms of starches was analyzed using FTIR (Figure 2). A series of overlapping peaks existed and located in $800-1300 \mathrm{~cm}^{-1}$ area, which is often referred to as the saccharide bands and vibration modes from the stretching of $\mathrm{COC}$ and $\mathrm{COO}$ and the bending mode of $\mathrm{COH}$ bonds, were the most intense in the mid-IR spectrum (Nakorn et al., 2009; Ulfa et al.,

Table 5. The three solutions obtained from the software

\begin{tabular}{lccccc}
\hline \multirow{2}{*}{ Solutions } & \multicolumn{2}{c}{ Independent variables } & \multicolumn{3}{c}{ Dependent variables } \\
\cline { 2 - 6 } & Temperature $\left({ }^{\circ} \mathrm{C}\right)$ & Reaction time (Min) & Solubility (\%) & Swelling power $(\mathrm{g} / \mathrm{g})$ & Water-binding capacity (\%) \\
\hline Solution 1 & 59.53 & 15 & 5.87 & 30.28 & 93.78 \\
Solution 2 & 59.59 & 14.95 & 5.87 & 30.26 & 93.79 \\
Solution 3 & 42.81 & 5 & 5.87 & 24.61 & 91.06 \\
\hline
\end{tabular}


(a)

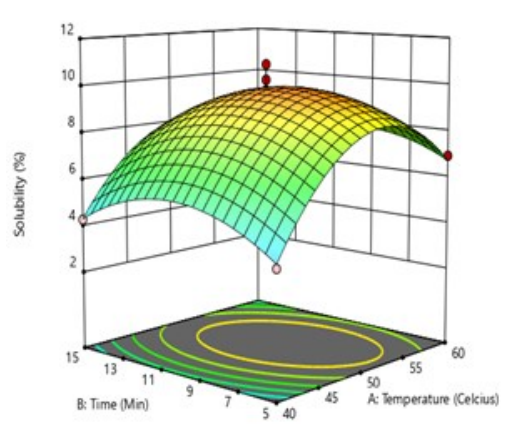

(b)

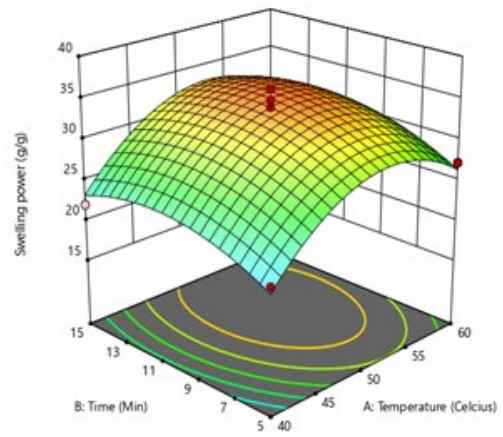

(c)

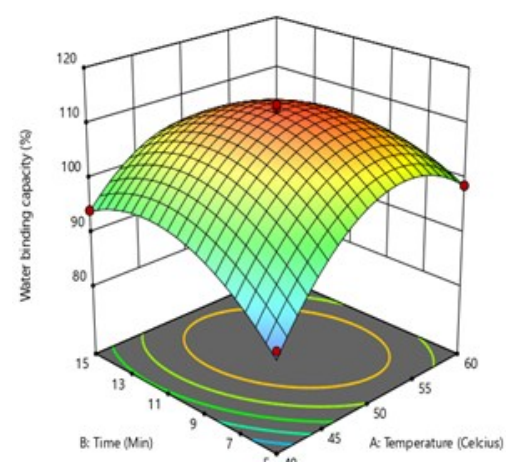

Figure 1. All 3D graphs showing the influence of temperature and reaction time on (a) solubility; (b) swelling power; (c) waterbinding capacity of pre-gelatinized starch. All the graphs are following the quadratic models suggested by the software.

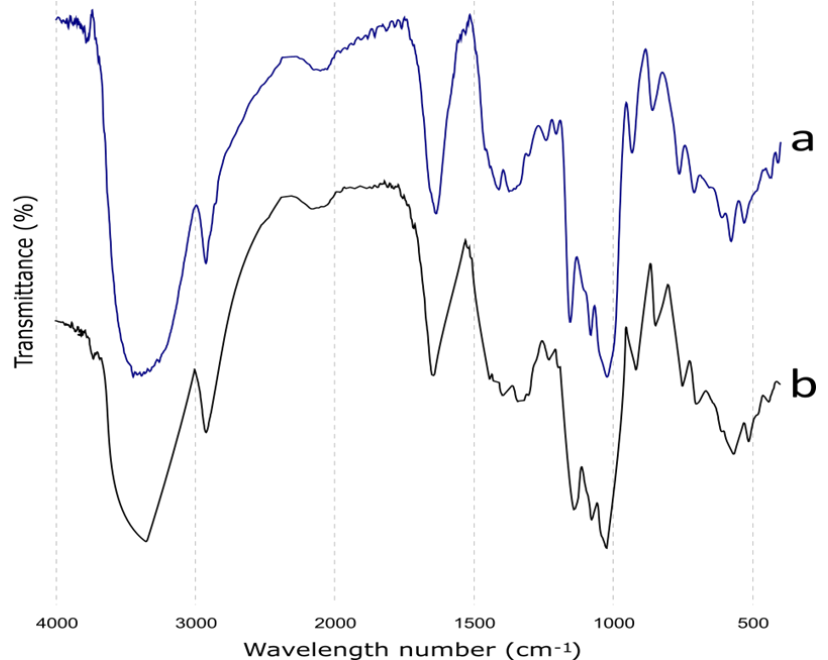

Figure 2. The images of Fourier-Transform Infrared (FTIR) spectra from native and pre-gelatinized starches: (a) native starch; (b) optimized pre-gelatinized starch

2020). As expected, there was no new peak in pregelatinized starch. However, there was a reduction in some of the peak intensity due to the treatment. The loss of crystallinity due to the heat treatment caused the hole and indentation which can be confirmed from the micrograph image (Figure 4).

The pasting analysis of starches was described as starch pasting characteristics. All starch pasting characteristics are presented in Figure 3. Pre-gelatinized starch showed a lower setback value, indicating better retrograde and syneresis properties than native starch. There was also a reduction in pasting temperature in RVA analysis which will favor the usage of starch in industry. The change of pasting characteristics was the result of granule disruption during the heating. The loss of granule integrity and crystallinity influenced the change of RVA curves. The lower peak viscosity of pregelatinized starch indicates the thermal forces on granule structure resulting in the disruption of the structure (Nakorn et al., 2009).

All starches micrographs are presented in Figure 4. Native starch shapes were round, ellipse, oval, or spherical shape. The pre-gelatinized starch showed a relatively bigger granule size and some of the granules were found to have exploded or melting (Lawal et al., 2015; Ulfa et al., 2020). These changes happened due to the higher swelling of granule as the temperature increases. The water will enter the granule as the swelling happened. As soon as the content leach out of the granule, the swelling will be bigger and explode with the rise of temperature. The pre-gelatinized starch micrograph showed that the partial pre-gelatinization happened as the result of the treatment.

\section{Conclusion}

Sweet potato starch drawbacks could be overcome by pre-gelatinization. Pre-gelatinized sweet potato starch could be made by heating the starch suspension at a certain temperature and time. The optimization process showed that heating the starch at $59.53^{\circ} \mathrm{C}$ for $15.00 \mathrm{mins}$ gave the optimum result in solubility, swelling power, and water-binding capacity. Pre-gelatinized starch is suggested to be used in instant product manufacturers such as porridge and infant products. 


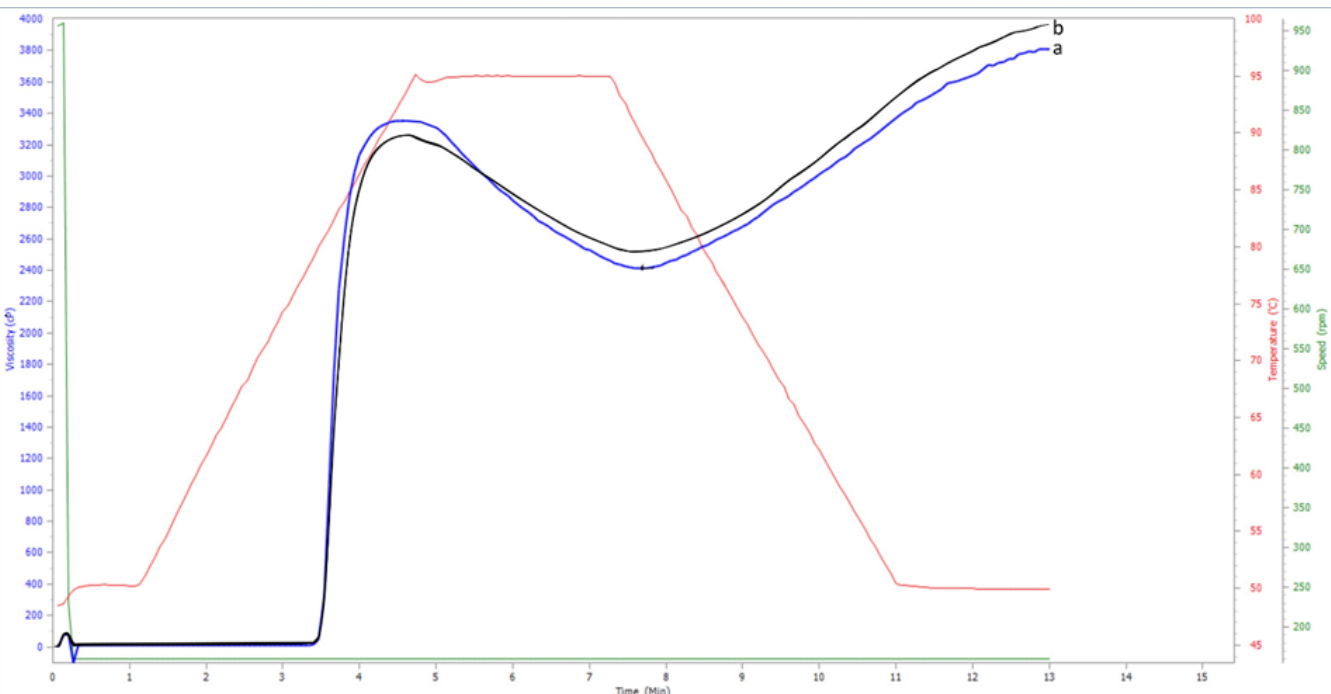

Figure 3. The images of rapid visco analyzer (RVA) pasting curves from native and pre-gelatinized starches: (a) native starch; (b) optimized pre-gelatinized starch

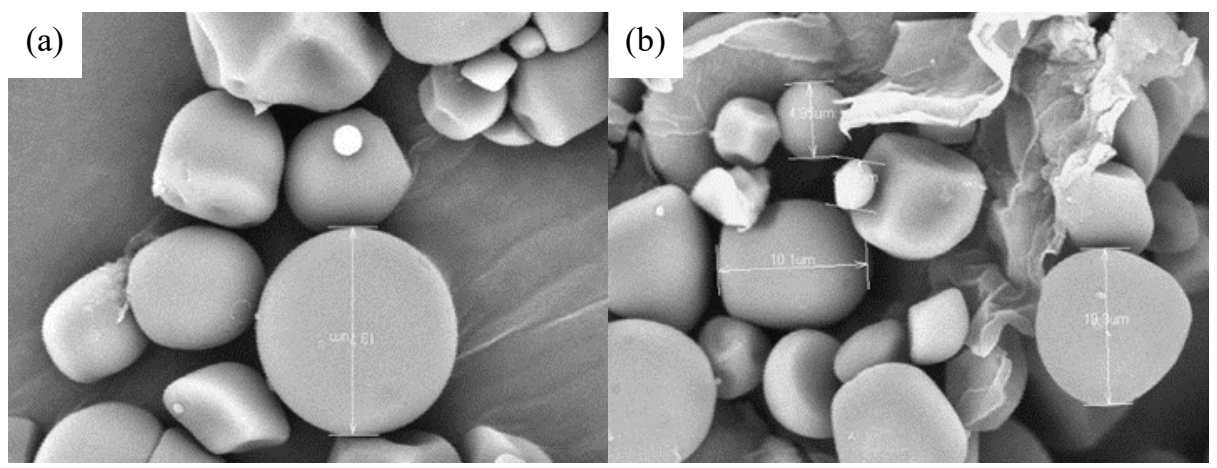

Figure 4. The micrograph images of (a) native starch; (b) pre-gelatinized starch. All images were scanned with 4000× magnification.

\section{Conflict of interest}

The authors declare no conflict of interest.

\section{Acknowledgments}

The research and publication of the article were funded by the Ministry of Research and Technology of the Republic of Indonesia for PMDSU program [contract number: 330.83/UN10.C10/PN/201].

\section{References}

Adedokun, M.O. and Itiola, O.A. (2010). Material properties and compaction characteristics of natural and pre-gelatinized forms of four starches. Carbohydrate Polymers, 79(4), 818-824. https:// doi.org/10.1016/j.carbpol.2009.10.009

Alebiowu, G. and Itiola, O.A. (2002). Compressional characteristics of native and pre-gelatinized Forms of sorghum, plantain and corn starches and the mechanical properties of their tablets. Drug Development and Industrial Pharmacy, 28(6), 663672. https://doi.org/https://doi.org/10.1081/DDC120003857

Ani, J.U., Okoro, U.C., Aneke, L.E., Onukwuli, O.D., Obi, I.O., Akpomie, K.G. and Ofomatah, A.C.
(2019). Application of response surface methodology for optimization of dissolved solids adsorption by activated coal. Applied Water Science, 9(3), 1-11. https://doi.org/10.1007/s13201-019-0943 $-7$

AOAC. (2005). Official methods of analysis. $18^{\text {th }}$ ed. Maryland, USA: Association of Official Analytical Chemist

Butt, N.A., Ali, T.M. and Hasnain, A. (2018). A Comprehensive Review on Scope, Characteristics and Applications of Instant Starches in Food Products. Annals. Food Science and Technology, 19 (1), 79-86.

FAOSTAT. (2020). Sweet potato. Retrieved on August 10, 2020, from FAO Website: www.fao.org/faostat/ en/\#data/QC

Hoover, R. (2001). Composition, molecular structure and physicochemical properties of tuber and root starches: A review. Carbohydrate Polymers, 45(3), 253-267. https://doi.org/https://doi.org/10.1016/ S0144-8617(00)00260-5

Juliano, B.O. (1981). International cooperative testing on the amylose content of milled rice. Starch/Stärke, 33 (5), 157-162. https://doi.org/10.1002/ star.19810330504 
Kankate, D., Panpalia, S.G., Kumar, K.J. and Kennedy, J.F. (2020). Studies to predict the effect of pregelatinization on excipient property of maize and potato starch blends. International Journal of Biological Macromolecules, 164, 1206-1214. https:// doi.org/10.1016/j.ijbiomac.2020.07.170

Kaur, M., Oberoi, D.P.S., Sogi, D.S. and Gill, B.S. (2011). Physicochemical, morphological and pasting properties of acid treated starches from different botanical sources. Journal of Food Science and Technology, 48(4), 460-465. https://doi.org/10.1007/ s13197-010-0126-x

Lawal, M.V., Odeniyi, M.A. and Itiola, O.A. (2015). Material and rheological properties of native, acetylated and pre-gelatinized forms of corn, cassava and sweet potato starches. Starch/Stärke, 67, 964 975. https://doi.org/10.1002/star.201500044

Liu, P., Zhang, B., Shen, Q., Hu, X. and Li, W. (2010). Preparation and structure analysis of noncrystalline granular starch preparation and structure analysis of noncrystalline granular starch. International Journal of Food Engineering, 6(4), 2. https:// doi.org/10.2202/1556-3758.1900

Liu, Y., Chen, J., Luo, S., Li, C., Ye, J., Liu, C. and Gilbert, R.G. (2017). Physicochemical and structural properties of pre-gelatinized starch prepared by improved extrusion cooking technology. Carbohydrate Polymers, 175, 265-272. https:// doi.org/10.1016/j.carbpol.2017.07.084

Mitch, L.E. (1983). Potato starch: Production and uses. In Whistler R., BeMiller, J. and Paschall, E. Starch: Chemistry and Technology. $2^{\text {nd }}$ ed., p. 279-280. USA: Academic Press Inc. https://doi.org/10.1016/ B978-0-12-746270-7.50020-3

Nakorn, K.N., Tongdang, T. and Sirivongpaisal, P. (2009). Crystallinity and rheological properties of pre-gelatinized rice starches differing in amylose content. Starch/Stärke, 61(2), 101-108. https:// doi.org/10.1002/star.200800008

Odeku, O.A., Schmid, W. and Picker-freyer, K.M. (2008). Material and tablet properties of pregelatinized (thermally modified) Dioscorea starches. European Journal of Pharmaceutics and Biopharmaceutics, 70(1), 357-371. https:// doi.org/10.1016/j.ejpb.2008.04.011

Pirt, S.J. and Whelan, W.J. (1951). The determination of starch by acid hydrolysis. Journal of the Science of Food and Agriculture, 2(5), 224-228. https://doi.org/ https://doi.org/10.1002/jsfa.2740020507

Ulfa, G.M., Putri, W.D.R., Fibrianto, K., Prihatiningtyas, R. and Widjanarko, S.B. (2020). The influence of temperature in swelling power, solubility and water- binding capacity of pregelatinised sweet potato starch. IOP Conference Series: Earth and Environmental Science, 475, 012036. https:// doi.org/10.1088/1755-1315/475/1/012036

Ulfa, G.M., Putri, W.D.R. and Widjanarko, S.B. (2019). The influence of sodium acetate anhydrous in swelling power, solubility and water-binding capacity of acetylated sweet potato starch. AIP Conference Proceedings, 2120, 050021. https:// doi.org/10.1063/1.5115697

Wang, H., Xiao, N., Wang, X., Zhao, X. and Zhang, H. (2019). Effect of pre-gelatinized starch on the characteristics, microstructures and quality attributes of glutinous rice flour and dumplings. Food Chemistry, 283, 248-256. https://doi.org/10.1016/ j.foodchem.2019.01.047

Zhu, F. and Sun, J. (2019). Physicochemical and sensory properties of steamed bread fortified with purple sweet potato flour. Food Bioscience, 30, 100411. https://doi.org/10.1016/j.fbio.2019.04.012

Zia-ud-Din, Xiong, H. and Fei, P. (2015). Physical and chemical modification of starches - A review. Critical Reviews in Food Science and Nutrition, 57 (12), 2691-2705. https:// doi.org/10.1080/10408398.2015.1087379 